\title{
Kinetics of precipitation and mechanical behavior of CuAlBe single crystal drawn-wires
}

\author{
P.M. Wasmer ${ }^{1}$, G. Mussot-Hoinard ${ }^{2 \mathrm{a}}$, S. Berveiller $^{1}$, E. Patoor ${ }^{1}$ and A. Eberhardt $^{3}$ \\ LPMM, \\ ${ }^{1}$ Arts et Métiers ParisTech, 57078 Metz, France \\ ${ }^{2}$ Université Paul Verlaine, 57045 Metz, France \\ ${ }^{3}$ ENIM, 57045 Metz, France
}

\begin{abstract}
The present work deals with the kinetics of precipitation of a CuAlBe single crystal alloy considering the influence of a pre-strain by wire-drawing. The single crystal is submitted to annealing parameters in order to obtain and compare the experimental starting points of the «time-temperature-precipitation» diagram without and with prestrain. Each sample has been observed by optical microscopy. Macroscopic tensile tests at room temperature were also undertaken to analyze the influence of wire drawing on the mechanical characteristics of the CuAlBe single crystal shape memory alloy.
\end{abstract}

\section{Introduction}

Shape memory alloys containing Copper and Aluminium are well studied since the years 1990. Studies on $\mathrm{CuAlBe}$ single crystal alloys have established good properties on fatigue life and dimensional stability [1].

In 1991, Zuniga [2] has studied the kinetics of precipitation for a polycrystalline CuAlBe alloy not deformed and proposed a «time-temperature-precipitation» diagram corresponding to the precipitation starting time at different temperatures. This precipitation leads to a hardening of the material.

The present work will focus on the study of a CuAlBe single crystal and show how the pre-forming wire drawing process affects the kinetics of precipitation at a given temperature and the mechanical properties.

\section{Material}

The composition of the CuAlBe alloy is 87.63 wt. \% Cu, 11.7 wt. \%Al and 0.67 wt. \% Be. The low addition of beryllium allows to reduce the Ms martensitic transformation point in accordance with the relationship proposed by Belkalha and co-authors [3]:

$$
\operatorname{Ms}\left({ }^{\circ} \mathrm{C}\right)=1245-71(\text { wt. } \% \mathrm{Al})-893(\text { wt.\%Be })
$$

According to this relationship, the expected martensitic transformation point, $\mathrm{Ms}$, is equal to $-184^{\circ} \mathrm{C}$ for the present $\mathrm{CuAlBe}$ single crystal. So, one can consider the alloy is in the domain of stable austenite at room temperature.

The single crystal has a $1.35 \mathrm{~mm}$ diameter; its microstructure is shown Fig. 1. The as-received wire is mostly austenitic: the $\beta$ phase constitutes the matrix. It appears that precipitation is already present, small amount of precipitates are observed. We assume this precipitation is inherited from the prior forming process of the single crystal wire.

\footnotetext{
a e-mails: genevieve.mussoteuniv-metz.fr
} 


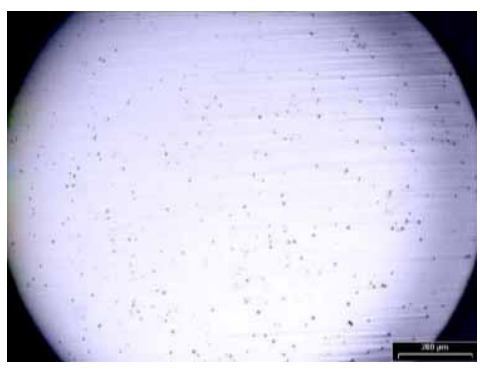

a)

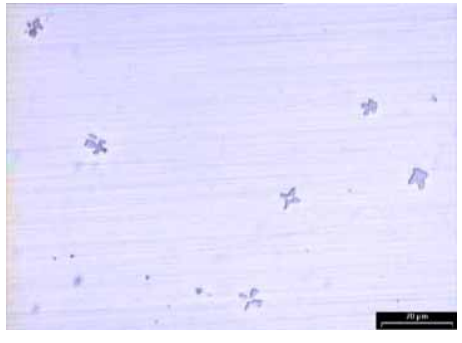

b)

Fig.1. Microstructural observation of the initial single crystal wire a) Cross section. b) Detailed view

\section{Microstructure evolution}

First, we present the microstructure evolution after annealing treatment in the as-received wire. Then using the drawn wire, we evaluate the influence of thermal treatments and deformation on phase distribution.

\subsection{Precipitation kinetics in the as-received wire}

Annealing treatments were performed at $500^{\circ} \mathrm{C}$, for various annealing times, in order to evaluate the precipitation kinetics (Fig. 2).

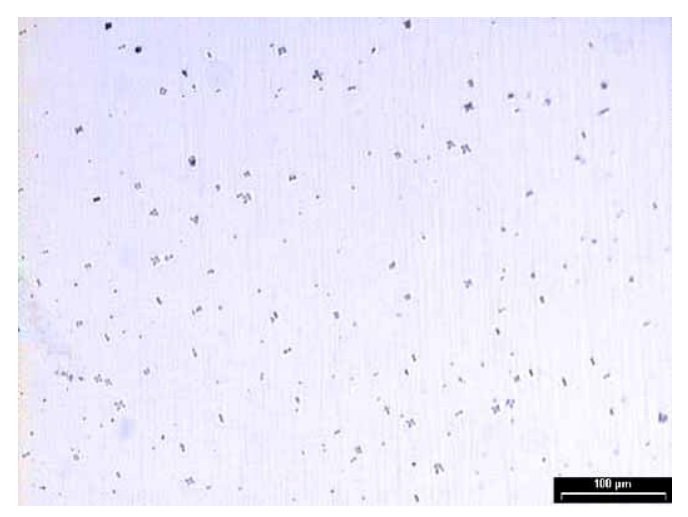

a)

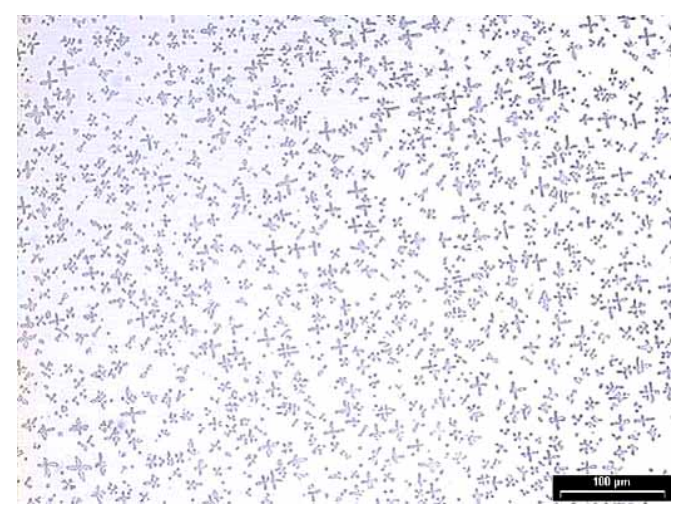

c)

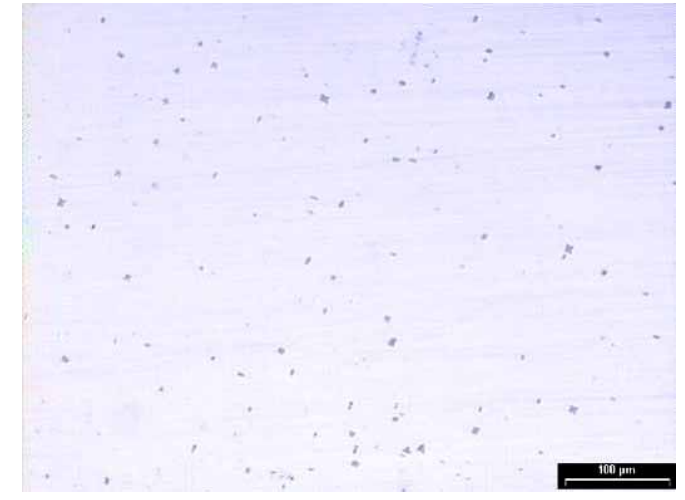

b)

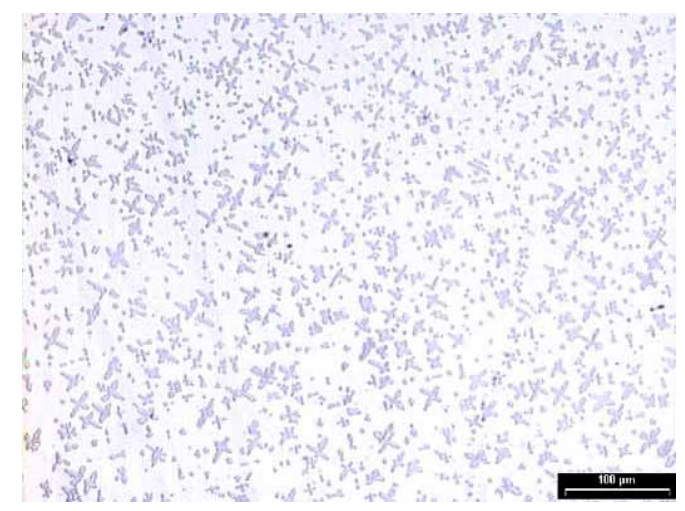

d)

Fig. 2. Evolution of the amount of precipitation with annealing time in as-received single crystal.

a) Before annealing. b) Annealed $1 \mathrm{~min}$ at $500^{\circ} \mathrm{C}$. c) Annealed $2 \mathrm{~min}$ at $500^{\circ} \mathrm{C}$. d) Annealed $1 \mathrm{~min}$ at $500^{\circ} \mathrm{C}$. 
As we previously noticed, precipitation is already present before any further annealing treatment (Fig. 2a). This has to be taken into account in the evaluation of the precipitation kinetics. After 1 minute annealing at $500^{\circ} \mathrm{C}$, precipitates density remains almost constant (Fig. 2b). However, after an annealing time of 2 minutes, the structure observed is very different: numbers of cross-shaped precipitated have appeared (Fig. 2 c).

Thus, we will consider precipitation occurs between 1 and 2 minutes of annealing at $500^{\circ} \mathrm{C}$. Moreover, it seems that the precipitation does not continue after 2 minutes, maybe having reached saturation: precipitation is very similar at 5 minutes to the state at 2 minutes (Fig. 2 d). Precipitates exhibit the characteristic shape of $\gamma_{2}$ phase. We can distinguish small ones, quite round (about $2 \mu \mathrm{m}$ ), and which will grow up as star-shaped ones (up to $10 \mu \mathrm{m})$. Moreover, the precipitates seem to be oriented in specific directions.

From these observations we may conclude that at $500^{\circ} \mathrm{C}$ the precipitation kinetics of this $\gamma_{2}$-like phase has a nucleation time slightly larger than $1 \mathrm{~min}$ and it reaches a saturation value for treatment time lightly larger than $2 \mathrm{~min}$.

\subsection{Influence of wire-drawing on precipitation kinetics}

We will now take interest in the wire-drawn single crystal properties: microstructure and precipitation behavior. The wire drawing was performed industrially, in one pass at $500^{\circ} \mathrm{C}$ followed by water quenching; the wire diameter reduction was such that it corresponds to $17 \%$ strain. .

\subsubsection{Microstructure after wire-drawing}

Fig. 3 presents the microstructure after wire-drawing.

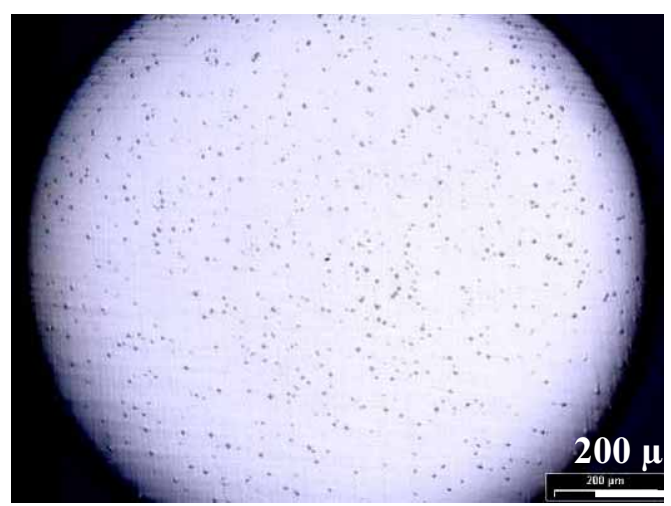

a)

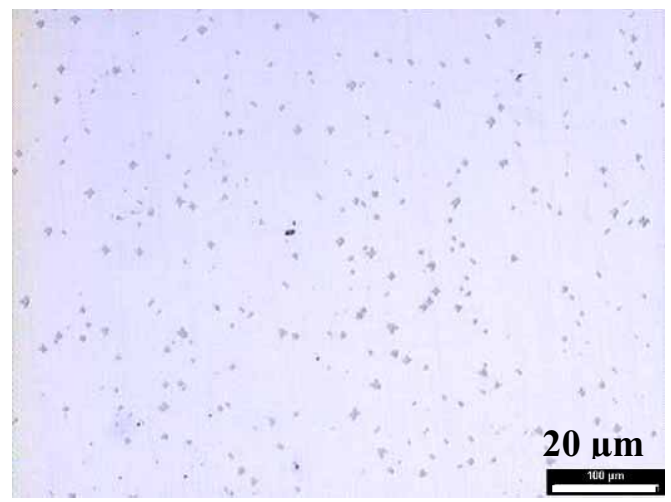

b)

Fig. 3. a) Microstructure observation of the wire-drawn single crystal wire ( $\varepsilon=17 \%)$; b) Detailed view.

There does not seem to be so many differences between the initial and the wire-drawn single crystal wire. The main phase is still austenite, with quite low proportion of small precipitates. This proportion appears a bit higher than that previously observed in the as received single crystal, but it is still far from the likely saturated precipitation density we have obtained after a 2 min annealing treatment at $500^{\circ} \mathrm{C}$. This result must be related to the very short time the wire experienced a heating up to $500^{\circ} \mathrm{C}$ during the drawing process, this time must be equivalent to the nucleation time required for this precipitation to occur.

\subsubsection{Annealed microstructure after wire-drawing}

We performed the same annealing treatments as for the as-received initial single crystal wire, various durations at $500^{\circ} \mathrm{C}$. Microstructures are plotted fig. 4 . 


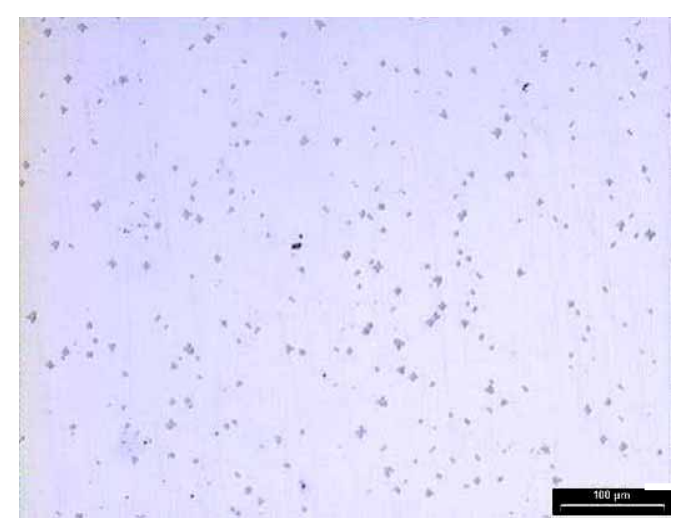

a)

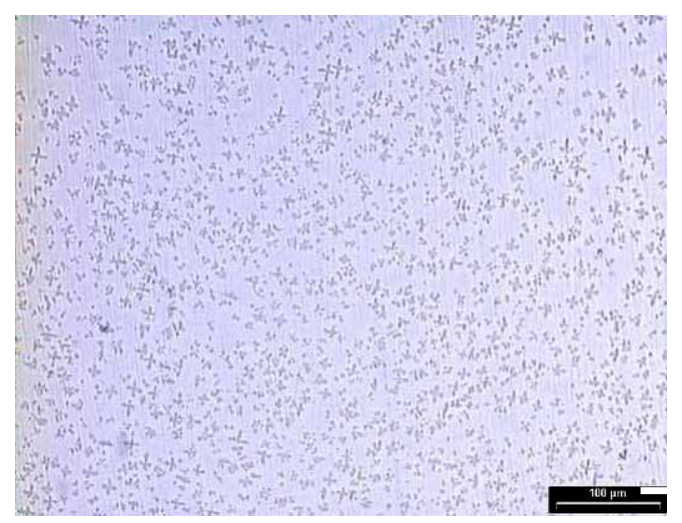

c)

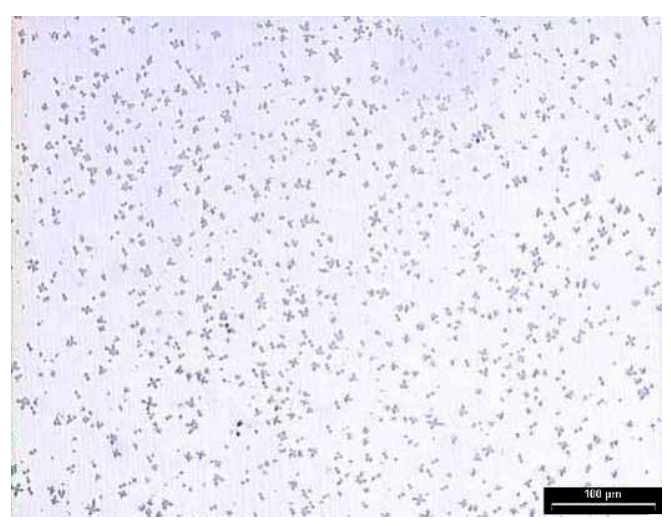

b)

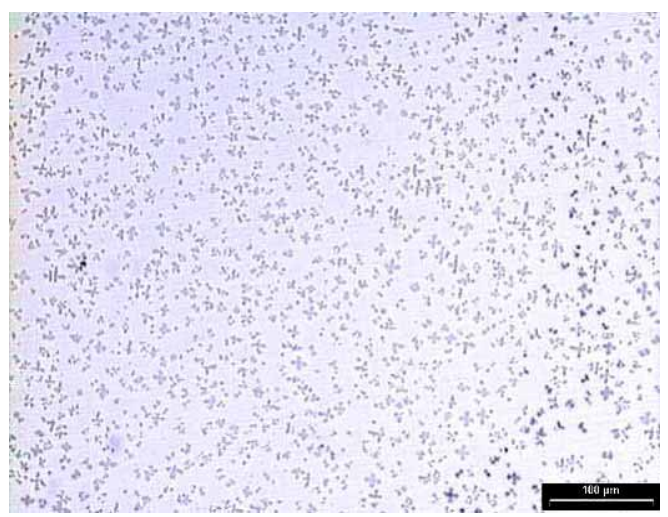

d)

Fig. 4. Evolution of precipitation with duration of thermal treatment at $500^{\circ} \mathrm{C}$ of the wire-drawn single crystal. a) initial state. b) $30 \mathrm{sec}$. c) 1 min. d) $5 \mathrm{~min}$.

Precipitation has already started after 30 seconds at $500^{\circ} \mathrm{C}$, and it reaches a likely saturated state after 1 minute: there is no visible evolution between 1 minute and 5 minutes of annealing. These times are shorter than the ones observed on the non-deformed wire. As a matter of fact, the wire has already been annealed during the wire-drawing process performed at $500^{\circ} \mathrm{C}$. However, this occurred necessarily during a short time, and is not sufficient to explain an acceleration of at least 30 seconds. Thus, we can consider that the work hardening induced by the wire-drawing will speed up the precipitation kinetics. Moreover precipitates density is bigger and precipitates are smaller in the deformed wire as compared to the non deformed one.

\section{Influence of wire-drawing on mechanical properties}

In order to evaluate mechanical behavior, tensile tests were performed at room temperature. The properties of the various microstructural states are compared.

\subsection{As-received wire}

Fig. 5 shows the macroscopic stress-strain curve of the initial single crystal wire during tensile tests at increasing maximum strain. 


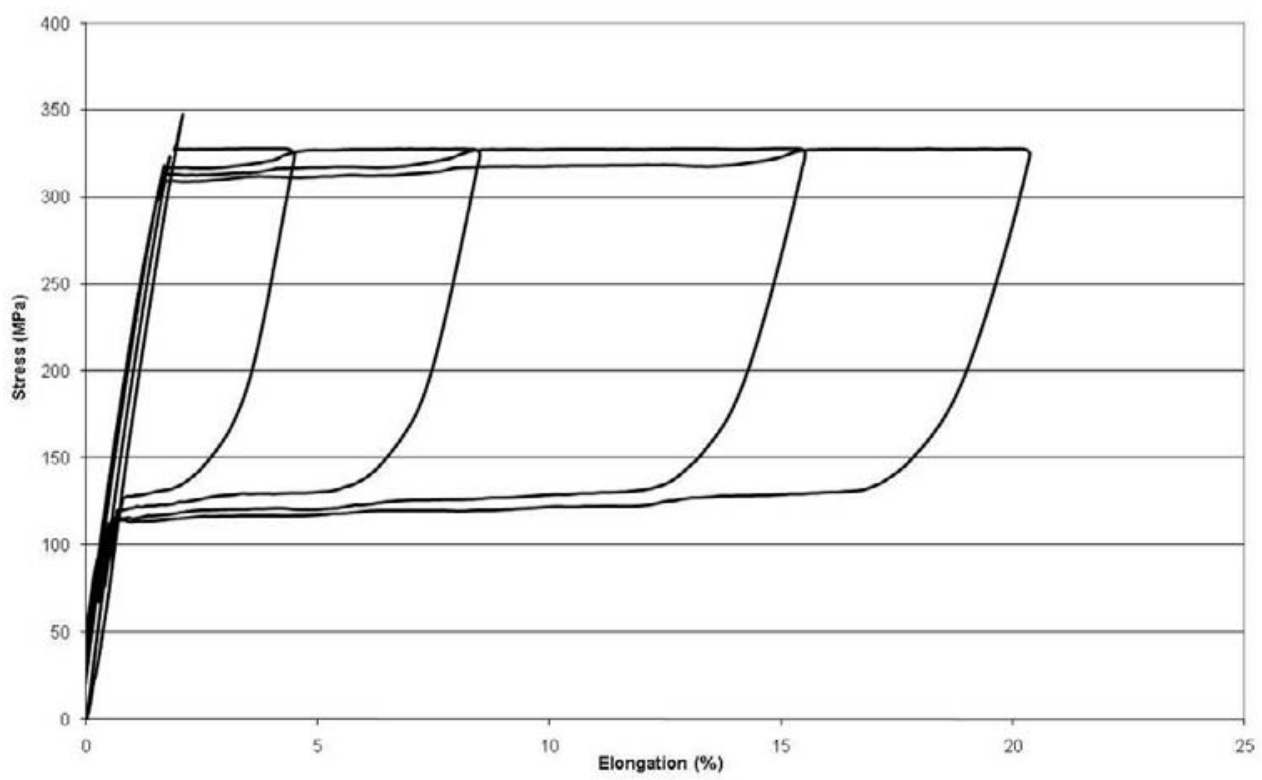

Fig. 5. Tensile test performed on the initial single crystal wire at room temperature

The martensitic transformation starts first for a stress of $\sigma_{\text {crit }}=330 \mathrm{MPa}$. On unloading, the reverse martensite-austenite transformation occurs around $130 \mathrm{MPa}$, which corresponds to a hysteresis of about 200 $\mathrm{MPa}$. For the next cycles, the stress level required to induce the martensitic transformation decreases a little. Indeed, the previous strains sustained by the wire have induced defects which will make easier the formation of martensite in these zones. Moreover, when the maximum level of strain of the previous cycles is reached, the transformation stress comes back to its initial value: $\sigma_{\text {crit }}=330 \mathrm{MPa}$.

\subsection{Mechanical behavior after wire-drawing}

Tensile tests were also performed on wire-drawn single crystal (see Fig. 6).

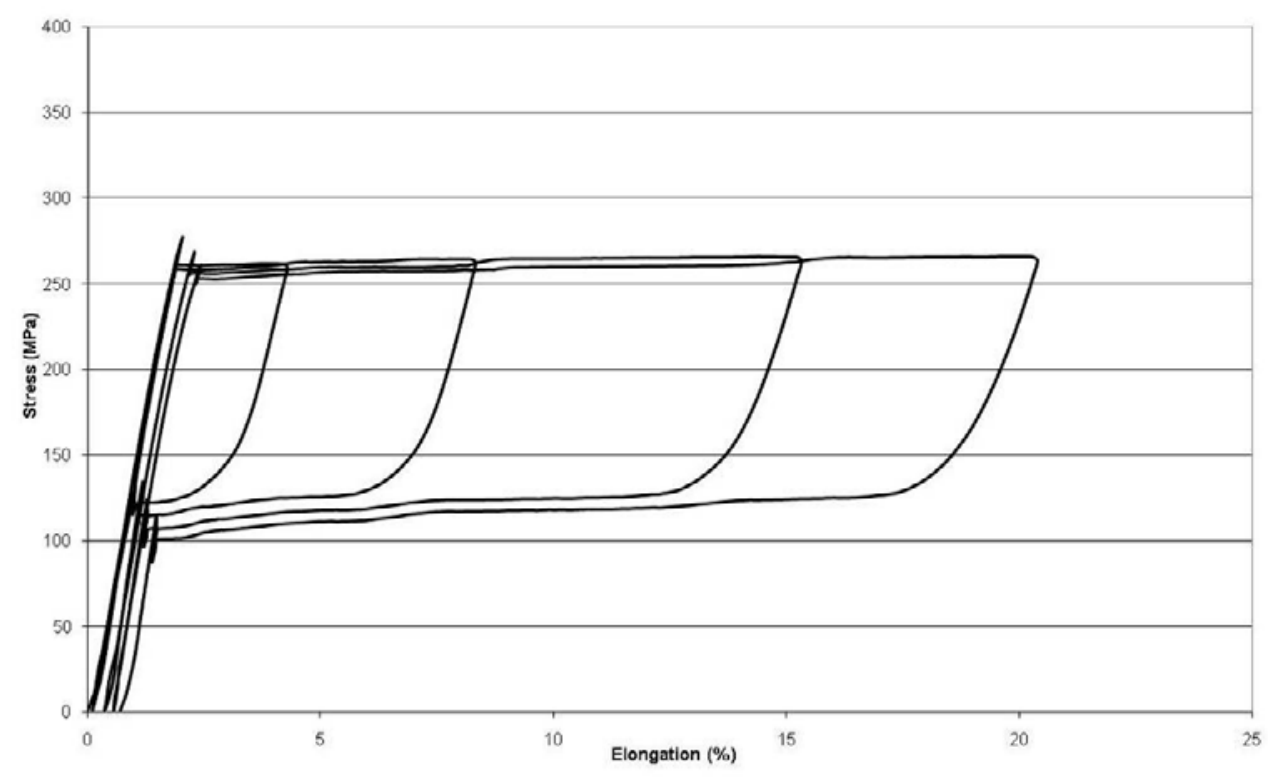

Fig. 6. Tensile test performed on the wire-drawn single crystal wire at room temperature

The global behaviour of the wire has not changed. It is still able to reach very high level of elongation (more than 20\%). However, the stress required to induce the martensitic transformation is lowered after wiredrawing: around $\sigma_{\text {crit }}=260 \mathrm{MPa}$ (we were at $\sigma_{\text {crit }}=330 \mathrm{MPa}$ for the initial wire). Similarly, the reverse 
transformation occurs at $\sigma_{\text {crit }}=120 \mathrm{MPa}\left(\sigma_{\text {crit }}=130 \mathrm{MPa}\right.$ for the as-received wire $)$ and the hysteresis amplitude is smaller.

\section{Conclusion}

In that work, we have studied the influence of a pre-strain on precipitation kinetics in a SMA single crystal and its further consequences on mechanical behaviour. We have shown that kinetics are shifted towards shorter times: pre-straining eases the precipitates formation. Moreover precipitates morphology are also affected: it evolves from a star-shaped morphology to a more round-shaped one. The martensitic transformation is also favoured: the pre-strained sample starts to transform for a lower critical stress than the non deformed one.

The authors are grateful to A. Blondel (Arts et Métiers ParisTech master student) as some results are parts of his master works.

\section{References}

[1] N. Siredey, A. Hautcoeur, A. Eberhardt, Mater. Sci. Eng., A396 296-301(2005).

[2] H. Zuniga, D. Rios-Jara, F.C. Lovey, G. Guenin, "Thermal stability of phase in a Cu-Al-Be shape memory alloy", J. Phys. IV, C-2 171-174 (1995)

[3] S. Belkahla, G. Guenin, "Martensitic transformation and metallurgical study of low temperature $\mathrm{Cu}-\mathrm{Al}-\mathrm{Be}$ ternary alloy", European symposium on martensitic transformation and shape memory properties", Aussois Fr, J. Phys. IV, C-4 145-150 (1991) 